'Krankenanstalt Rudolfstiftung.

${ }^{2}$ Radiological Department, Krankenanstalt Rudolfstiftung, Vienna, Austria. aPhD.

Recibido el 18 de febrero de 2015, aceptado el 28 de julio de 2015.

Corresponding author: Josef Finsterer, MD, PhD Postfach 20 1180 Vienna. Austria, Europe. Tel. +43-1-71165-92085 Fax. $+43-1-4781711$ fifigs1@yahoo.de

\section{Multiorgan disorder syndrome (MODS) in an octagenarian suggests mitochondrial disorder}

\begin{abstract}
Non-syndromic, multi-organ mitochondrial disorders (MIDs) are frequently missed if treating physicians are not aware of them. We report a 85 years old Caucasian male, referred for tonic-clonic seizures, presenting with a plethora of abnormalities, including neurodermitis, atopic dermatitis, diabetes, hypertension, renal insufficiency, non-specific colitis, urine bladder lithiasis, bilateral cataracts, atrial fibrillation, diverticulosis, polyneuropathy, vitamin-D-deficien$c y$, renal cysts, left anterior hemi-block, right bundle branch block, pulmonary artery hypertension, and heart failure. Neurological investigations revealed ptosis, quadriparesis, fasciculations, dysarthria, dysdiadochokinesia, tremor, hyperkinesia, ataxia, leukoencephalopathy, and basal ganglia calcification. Based upon this combination of abnormalities a non-syndromic mitochondrial multi-organ disorder syndrome (MIMODS, encephalo-myo-cardiomyopathy) was diagnosed.

(Rev Med Chile 2015; 143: 1210-1214)
\end{abstract}

Key words: Cardiomyopathies; Mitochondrial diseases; Seizures.

\section{Síndrome mitocondrial no sindrómico con fallas de múltiples sistemas. Presentación de un caso}

Las alteraciones mitocondriales no sindrómicas y mutisistémicas pueden ser pasadas por alto si no se está consciente de su existencia. Presentamos un hombre de 85 años, referido por convulsiones tónico clónicas, que presentaba una plétora de anomalías tales como neurodermatitis, dermatitis atópica, diabetes, hipertensión, insuficiencia renal, colitis no específica, litiasis vesical, cataratas bilaterales, fibrilación auricular, diverticulosis, polineuropatía, deficiencia de vitamina $D$, quistes renales, hemibloqueo izquierdo anterior y bloqueo de rama derecha, hipertensión pulmonar e insuficiencia cardíaca. El estudio neurológico reveló la presencia de ptosis, cuadriparesia, fasciculaciones, disartria, disdiadocoquinesia, temblor, hiperquinesia, ataxia, leucoencefalopatía y calcificación de ganglios basales. Basados en estos hallazgos, se diagnosticó un síndrome mitocondrial no sindrómico con fallas de múltiples sistemas.

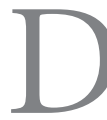

iagnosing mitochondrial disorders (MIDs) is challenging despite recent advances in the work-up of MIDs ${ }^{1}$. Particularly, in non-syndromic MIDs manifesting in adulthood with single non-specific abnormalities, MIDs are frequently missed. However, the combination of certain phenotypic aspects may suggest such a diagnosis, as in the following case. 


\section{Case report}

The patient is a 85 year-old Caucasian male, height $165 \mathrm{~cm}$, weight $59 \mathrm{~kg}$, with long-time multiple diseases, who was referred to the neurologist after a first tonic-clonic seizure, possibly triggered by hypoglycemia. His previous individual history was noteworthy for recurrent bilateral inguinal hernia requiring surgery 3-4 times starting at age 53, recurrent dermatological problems, such as neurodermitis and atopic dermatitis since age 59, diabetes mellitus since age 65 , prostate hyperplasia requiring surgery at age 77 (2006), colitis ulcerosa with non-specific inflammatory alterations on colonic biopsy at age 78 (2006), recurrent urinary bladder lithiasis at age 78 , bilateral cataract surgery at age 78 (2007), permanent atrial fibrillation since age 80 (2008), diverticulosis since age 82 (2011), well controlled arterial hypertension since at least age 83, renal insufficiency since at least age 83, and polyneuropathy, vitamin-D-deficiency, renal cysts, left anterior hemiblock and right bundle branch block, pulmonary hypertension, and heart failure with recurrently elevated proBNP levels since at least age 84 (2013). His family history was negative for neuromuscular disorders or epilepsy, but his mother had died one month after his birth from an acute cardiac problem and he had to spend the entire first year of his life in an incubator for unknown reasons. Since three years he required a walker because of gait disturbance.

At age 85 (9/2014) he was admitted for heart failure. After modification of the anti-diabetic therapy he experienced a first tonic clonic seizure. Neurologic exam was noteworthy for bilateral ptosis, hypoacusis, facial wasting, mild dysarthria, diffuse weakness (M5-) and wasting of the upper and lower limb muscles, rapid descent of both arms, fasciculations of the intrinsic hand muscles, dysdiadochokinesia, symmetric resting and postural tremor, bilateral hyperkinesias, bilateral ataxia, and absent tendon reflexes on the lower limbs. Blood chemical exams revealed anemia, mild renal insufficiency, hypocalcemia, elevated HbAlc, elevated proBNP, and vitamin-D-deficiency (Table 1). Cerebral MRI showed leucencephalopathy and bilateral basal ganglia calcification (Figure 1). EEG did not show paroxysmal activity. Clinical cardiologic exam revealed signs of heart failure. ECG showed atrial fibrillation, left anterior hemiblock, and right bundle branch block (bifascicular block). Echocardiography showed tricuspid insufficiency-3, mitral insufficiency-1, an enlarged left atrium, pulmonary artery hypertension,

Table 1. Blood chemical results of the described patient

\begin{tabular}{|lccccccc|}
\hline $\begin{array}{l}\text { Parameter } \\
\text { (normal range) }\end{array}$ & $\mathbf{3 0 . 9}$ & $\mathbf{1 3 . 3 .}$ & $\mathbf{1 8 . 1 2}$ & $\mathbf{1 6 . 2}$ & $\mathbf{2 7 . 2}$ & $\mathbf{6 . 5 .}$ & $\mathbf{1 4 . 9 .}$ \\
\hline Erythrocytes $(4.2-5.5 \mathrm{~T} / \mathrm{l})$ & $\mathbf{2 0 1 1}$ & $\mathbf{2 0 1 2}$ & $\mathbf{2 0 1 2}$ & $\mathbf{2 0 1 3}$ & $\mathbf{2 0 1 3}$ & $\mathbf{2 0 1 3}$ & $\mathbf{2 0 1 4}$ \\
\hline Hemoglobin $(14-17 \mathrm{~g} / \mathrm{dl})$ & $\mathbf{1 3 . 5}$ & 14.4 & $\mathbf{1 2 . 1}$ & $\mathbf{1 3 . 7}$ & $\mathbf{1 3 . 0}$ & $\mathbf{1 2 . 7}$ & $\mathbf{1 1 . 8}$ \\
\hline Hematocrit $(40-50 \%)$ & $\mathbf{3 9 . 0}$ & 43.3 & $\mathbf{3 7 . 6}$ & $\mathbf{3 9 . 8}$ & 40.2 & $\mathbf{3 8 . 4}$ & $\mathbf{3 6 . 9}$ \\
\hline Creatinine $(<1.1 \mathrm{mg} / \mathrm{dl})$ & $\mathbf{1 . 7 1}$ & $\mathbf{1 . 1 2}$ & $\mathbf{1 . 3 2}$ & $\mathbf{1 . 5 3}$ & $\mathbf{1 . 2 9}$ & 1.09 & 1.08 \\
\hline GFR $\left(>90 \mathrm{ml} / \mathrm{min} / 1.73 \mathrm{~m}^{2}\right)$ & $\mathbf{4 1}$ & $\mathbf{6 7}$ & $\mathbf{5 2}$ & $\mathbf{3 3}$ & $\mathbf{5 3}$ & $>60$ & $\mathbf{6 5}$ \\
\hline Uric acid $(3.5-7.0 \mathrm{mg} / \mathrm{dl})$ & $\mathbf{9 . 6}$ & 6.8 & $\mathbf{8 . 6}$ & $\mathrm{nd}$ & $\mathrm{nd}$ & $\mathbf{7 . 7}$ & 6.3 \\
\hline HbA1c $(0-6.0 \%)$ & $\mathbf{8 . 8}$ & $\mathbf{8 . 5}$ & $\mathbf{9 . 0}$ & $\mathbf{7 . 5}$ & $\mathrm{nd}$ & $\mathbf{7 . 3}$ & $\mathbf{8 . 5}$ \\
\hline Creatine-kinase $(<170 \mathrm{U} / \mathrm{l})$ & 123 & 137 & 158 & $\mathbf{1 7 5}$ & 111 & 105 & 158 \\
\hline proBNP $(<100 \mathrm{ng} / \mathrm{l})$ & 21 & 15 & 15 & 23 & 24 & 27 & $\mathrm{Nd}$ \\
\hline Vitamni-D $(>30 \mathrm{ng} / \mathrm{ml})$ & 31 & 20 & 15 & 30 & 24 & 50 & 28 \\
\hline GGT $(0-60 \mathrm{U} / \mathrm{l})$ & 9 & 11 & 11 & 12 & 13 & 21 & 14 \\
\hline Cholesterol $(150-200 \mathrm{mg} / \mathrm{dl})$ & 144 & 176 & $\mathbf{1 3 9}$ & 131 & $\mathrm{nd}$ & 115 & 154 \\
\hline Triglycerides $(50-170 \mathrm{mg} / \mathrm{dl})$ & 91 & 77 & 92 & 133 & $\mathrm{nd}$ & 93 & $\mathrm{nd}$ \\
\hline
\end{tabular}

GFR: glomerular filtration rate, GOT: glutamate-oxalate transaminase, GPT: glutamate-pyruvate transaminase, GGT: gamma-glutamyl transpeptidase. 

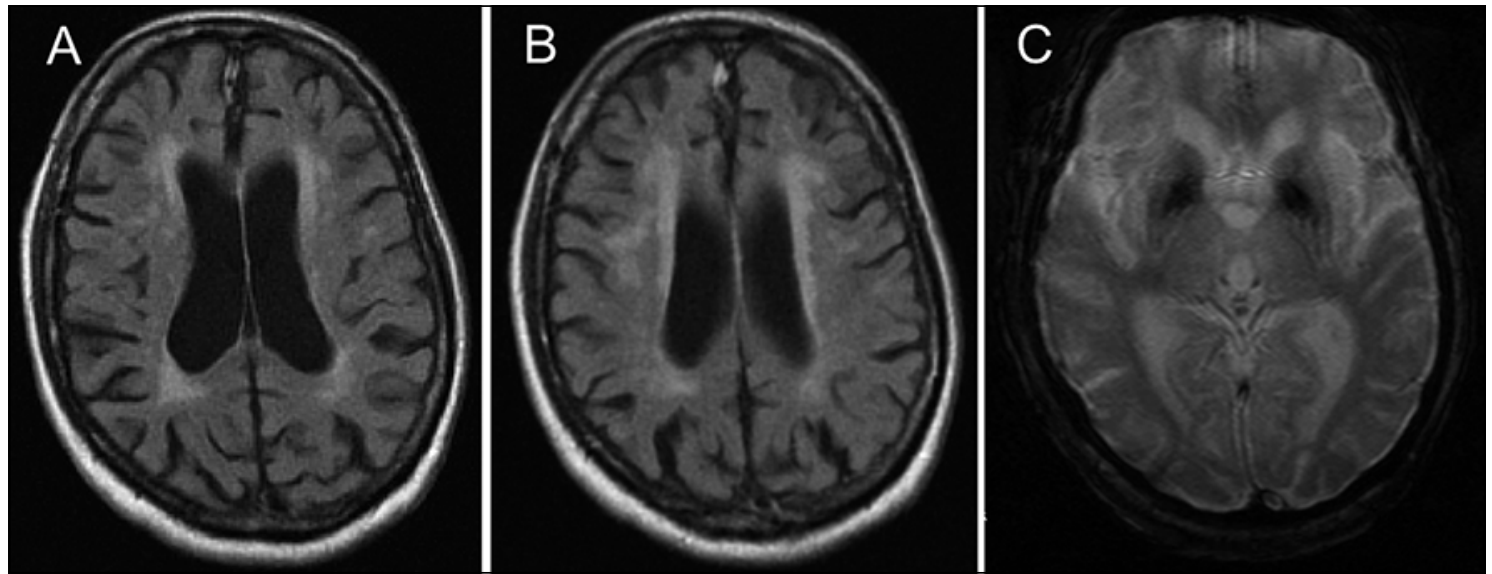

Figure 1. Cerebral MRI of the presented patient showing leucaraiosis with hyperintense perventricular areas and central white matter lesions with right-sided predominance (A, B, axial, T2 blade). On axial T2fw hemo images hypointensity of the basal ganglia corresponding to calcifications can be seen $(\mathbf{C})$.

and pericardial effusion. Abdominal ultrasound revealed a right-sided double kidney and renal cysts bilaterally. After recompensation, he was dismissed with a medication of levetirazetam, mesalazine, phenprocoumon, spironolactone, bisoprolol, furosemide, lingagliptin, and insulin. History and instrumental findings were strongly suggestive of a MID.

\section{Discussion}

The presented patient is interesting for epilepsy first manifesting not earlier than at age 85, for multisystem disease affecting the brain, peripheral nerves, skeletal muscle, eyes, ears, endocrine organs, the heart, the gastrointestinal tract, the kidneys, the bone marrow, and the skin. In the cerebrum the MID manifested as epilepsy, leucaraiosis, basal ganglia calcifications, hyperkinesias, dysdiadochokinesia, and tremor. In the peripheral nervous system, the disease manifested as polyneuropathy and myopathy. In the eyes it manifested as cataract and in the ears as hypoacusis. In the endocrine system it manifested as diabetes mellitus, short stature, hypocalcemia, and presumably hypogonadism (he had no children). In the heart the MID manifested as arrhythmias (atrial fibrillation, left anterior hemiblock, right bundle branch block) and as cardiomyopathy with heart failure and systolic dysfunction, in the gastrointestinal tract as colitis with recurrent diarrhoea, and sig- madiverticulosis, in the urogenital tract as renal failure, double kidney, urine bladder lithiasis, and renal cysts, in the bone marrow as anemia, and in the skin as atopic dermatitis respectively neurodermitis. Based upon this combination of abnormalities a non-syndromic mitochondrial multiorgan disorder syndrome (MIMODS, encephalo-myo-cardiopathy) was diagnosed.

Arguments for a MID in the presented patient are the multisystem nature of the disease and the combination of core features of MIDs, such as epilepsy, basal ganglia calcification, ptosis, hearing loss, myopathy, neuropathy, cataract, diabetes, renal insufficiency, anemia, and the cardiac abnormalities $^{2}$. A third argument for a MID is that no other causes explain the plethora of abnormalities present in this patient and that such a combination has been described in previous reports about patients with a MID. A biochemical or genetic confirmation of the diagnosis is eligible but does not appear to be needed in the light of the clinical presentation, obviously in line with a MID, the decreasing health budgets, the frequent inaccuracy of muscle biopsy and biochemical findings in MIDs, the invasive nature of many investigations, and the increased age of the patient. A further argument for a MID is the late onset of colitis at age 78, which is unusual, and excludes colitis ulcerosa. Unusual is also the late onset of the MID, which should not be mixed up with physiological ageing.

The patient is further interesting for dermato- 
Table 2. Dermatological problems in mitochondrial disorder

\begin{tabular}{|llc|}
\hline Mitochondrial disorder & Dermatological disorder & Reference \\
\hline Pearson syndrome & Flaky skin & {$[3]$} \\
& Transient alopecia & {$[3]$} \\
MELAS & Cutaneous zygomycosis & {$[4]$} \\
& Atopic dermatitis & {$[6]$} \\
& Local melanoderma & {$[6]$} \\
& Asymmetric vascular dilatation & {$[7]$} \\
Kearns Sayre syndrome & Purpuric macules of sole + palms & {$[8]$} \\
MSL & Dermatological problems & {$[9]$} \\
MERRF & Hyperpigmentation & {$[10]$} \\
Leigh syndrome & Lipoma of the dermis & {$[11]$} \\
Ras-MAPK disorders & Skin lipomata & {$[12]$} \\
m.3243A $>$ G & Hypertrichosis & {$[13]$} \\
Non-syndromic MID & Lentiges & {$[14]$} \\
& Lipomas & {$[5]$} \\
\hline
\end{tabular}

MSL: multiple symmetric lipomatosis.

logical involvement in the MID. Dermatological abnormalities in MIDs are rare but have been occasionally reported ${ }^{3}$. Dermatological abnormalities associated with MIDs include psoriasis, skleroderma, neurodermitis, atopic dermatitis, hyperpigmentation, flaky skin ${ }^{3}$, transient alopecia $^{3}$, asymmetric vascular dilatation, purpuric macules of the sole and palma, lentiges, cutaneous zygomycosis ${ }^{4}$, dermal lipomata, or local melanoderma (Table 2). Dermatological abnormalities in MIDs often go undetected and are frequently not regarded as a manifestation of a MID. However, dermatological abnormalities have been previously reported as clinical features of a MID (Table 1). In a study of 140 children with various MIDs 14 (10\%) presented with dermatological abnormalities $^{5}$. All 14 patients had biochemical indications for respiratory chain defects and 6 patients $\mathrm{mtDNA}$ rearrangements and one carried the $\mathrm{m} .3243 \mathrm{~A}>\mathrm{G}$ mutation ${ }^{5}$. mtDNA rearrangements in skin fibroblasts of patients with MIDs indicate that the skin and hairs may be phenotypically involved in MIDs ${ }^{5}$. Whether the prevalence of dermatological tumours is increased in MIDs remains unproven.

This case shows that non-syndromic, multisystem MIDs in adults may be missed and diagnosed very late in life, that the combination of key features of a MID strongly suggests a MID, and that complex and costly diagnostic work-up for MID is abdicable with a clinical presentation as in the presented case. Treating physicians should be aware of MIDs and should apply symptomatic therapeutic measures and avoid any mitochondrion-toxic medication as a general therapeutic approach to these patients.

\section{References}

1. Chi CS. Diagnostic Approach in Infants and Children with Mitochondrial Diseases. Pediatr Neonatol 2014 Aug 20. pii: S1875-9572(14)00099-0. doi: 10.1016/j. pedneo.2014.03.009.

2. Rötig A. Renal disease and mitochondrial genetics. J Nephrol 2003; 16: 286-92. 
3. Lacbawan F, Tifft CJ, Luban NL, Schmandt SM, Guerrera $\mathrm{M}$, et al. Clinical heterogeneity in mitochondrial DNA deletion disorders: a diagnostic challenge of Pearson syndrome. Am J Med Genet 2000; 95: 266-8.

4. Kefala-Agoropoulou K, Farmaki E, Tsiouris J, Roilides E, Velegraki A. Cutaneous zygomycosis in an infant with Pearson syndrome. Pediatr Blood Cancer 2008; 50: 93940.

5. Bodemer C, Rötig A, Rustin P, Cormier V, Niaudet P, Saudubray JM, et al. Hair and skin disorders as signs of mitochondrial disease. Pediatrics 1999; 103: 428-33.

6. Pronicki M, Sykut-Cegielska J, Mierzewska H, Tońska K, Karczmarewicz E, Iwanicka K, et al. Diversity of clinical symptoms in A3243G mitochondrial DNA mutation (MELAS syndrome mutation). Med Sci Monit 2002; 8: CR767-73.

7. Horiguchi Y, Fujii T, Imamura S. Purpuric cutaneous manifestations in mitochondrial encephalomyopathy. J Dermatol 1991; 18: 295-301.

8. Kaufman KR, Zuber N, Rueda-Lara MA, Tobia A. MELAS with recurrent complex partial seizures, nonconvulsive status epilepticus, psychosis, and behavioral disturbances: case analysis with literature review. Epilepsy Behav 2010; 18: 494-7.
9. Artuch R, Pavía C, Playán A, Vilaseca MA, Colomer J, Valls C, et al. Multiple endocrine involvement in two pediatric patients with Kearns-Sayre syndrome. Horm Res 1998; 50: 99-104.

10. Plummer C, Spring PJ, Marotta R, Chin J, Taylor G, Sharpe D, et al. Multiple Symmetrical Lipomatosis-a mitochondrial disorder of brown fat. Mitochondrion 2013; 13: 269-76.

11. Teive HA, Munhoz RP, Muzzio JA, Scola RH, Kay CK, Raskin S, et al. Cerebellar ataxia, myoclonus, cervical lipomas, and MERRF syndrome. Case report. Mov Disord 2008; 23: 1191-2.

12. Baertling F, Mayatepek E, Distelmaier F. Hypertrichosis in presymptomatic mitochondrial disease. J Inherit Metab Dis 2013; 36: 1081-2.

13. Kleefstra T, Wortmann SB, Rodenburg RJ, Bongers EM, Hadzsiev K, Noordam C, et al. Mitochondrial dysfunction and organic aciduria in five patients carrying mutations in the Ras-MAPK pathway. Eur J Hum Genet 2011; 19: 138-44.

14. Suzuki Y, Nishimaki K, Taniyama M, Muramatsu T, Atsumi Y, Matsuoka K, et al. Lipoma and opthalmoplegia in mitochondrial diabetes associated with small heteroplasmy level of 3243 tRNA(Leu(UUR)) mutation. Diabetes Res Clin Pract 2004; 63: 225-9. 